\title{
Persistência de palhada e liberação de nutrientes do nabo forrageiro no plantio direto
}

\author{
Carlos Alexandre Costa Crusciol(1), Roberto Luiz Cottica(2), Eduardo do Valle Lima ${ }^{(3)}$, Marcelo Andreotti(4), \\ Edemar Moro ${ }^{(2)}$ e Edílson Marcon ${ }^{(2)}$
}

\begin{abstract}
(1)Universidade Estadual Paulista (Unesp), Fac. de Ciências Agronômicas, Caixa Postal 237, CEP 18603-970 Botucatu, SP. E-mail: crusciol@fca.unesp.br (2)Universidade Estadual do Oeste do Paraná, Centro de Ciências Agrárias, Campus de Marechal Cândido Rondon, CEP 85960-000 Marechal Cândido Rondon, PR. (3)Universidade Federal Rural da Amazônia, CEP 66077-530 Belém, PA. E-mail: valle.eduardo@ufra.edu.br (4)Unesp, Fac. de Engenharia, Caixa Postal 31, CEP 15385-000 llha Solteira, SP. E-mail: dreotti@agr.feis.unesp.br
\end{abstract}

\begin{abstract}
Resumo - A palhada das plantas de cobertura, mantida sobre o solo no plantio direto, representa uma reserva de nutrientes para cultivos subseqüentes. O objetivo deste trabalho foi avaliar a decomposição e a liberação de macronutrientes de resíduos de nabo forrageiro. O experimento foi realizado no campo, durante o ano de 1998, no Município de Marechal Cândido Rondon, PR. O nabo forrageiro foi dessecado e manejado com rolo-faca 30 dias após a emergência. Avaliaram-se a persistência de palhada e a liberação de nutrientes dos resíduos aos $0,13,35$ e 53 dias após o manejo. O delineamento experimental foi de blocos casualizados, com quatro repetições. O nabo forrageiro produziu, até o estádio de pré-florescimento, elevada quantidade de massa seca da parte aérea em cultivo de inverno (2.938 $\mathrm{kg} \mathrm{ha}^{-1}$ ), acumulando 57,2, 15,3, 85,7,37,4, 12,5 e 14,0 $\mathrm{kg} \mathrm{ha}^{-1}$, respectivamente, de $\mathrm{N}$, $\mathrm{P}, \mathrm{K}, \mathrm{Ca}, \mathrm{Mg}$ e S. O manejo do nabo forrageiro no estádio de pré-florescimento apresenta rápida degradação da palhada, acarretando liberação de quantidades significativas de macronutrientes. Os nutrientes disponibilizados em maior quantidade e velocidade para a cultura subseqüente, são o K e o N. A maior velocidade de liberação de macronutrientes pelo nabo forrageiro ocorre no período compreendido entre 10 e 20 dias após o manejo da fitomassa.
\end{abstract}

Termos para indexação: Raphanus sativus, resíduo vegetal, degradação de fitomassa, reciclagem de nutrientes, taxa de decomposição.

\section{Persistence and nutrients release of forage turnip straw utilized as mulching in no-tillage crop system}

\begin{abstract}
Straw of covering plants kept on soil surface in no-tillage system is an important source of nutrients for subsequent tillage. The objective of this work was to evaluate decomposition and macronutrients release from forage turnip residues. The experiment was set under field conditions during 1998 in Marechal Cândido Rondon, PR, Brazil. Forage turnip plants were desiccated and lodged 30 days after emergence. Straw persistence and nutrient release were evaluated at $0,13,35$ and 53 days after management. The experimental design was a randomized block with four replications. Until pre-flowering stage, the forage turnip showed a great dry matter yield $\left(2,938 \mathrm{~kg} \mathrm{ha}^{-1}\right)$ during winter growing and 57.2, 15.3, 85.7, 37.4, 12.5 and $14.0 \mathrm{~kg} \mathrm{ha}^{-1}$ of N, P, K, Ca, Mg and $\mathrm{S}$ were respectively accumulated. Forage turnip management at pre-flowering stage cause a quick straw degradation and macronutrients release. Potassium and nitrogen were released in the highest amounts and in the shortest time to the subsequent tillage. Quickest liberation of nutrients occurred between 10 to 20 days after plant management.
\end{abstract}

Index terms: Raphanus sativus, plant residue, phytomass degradation, nutrient recycling, decomposition rate.

\section{Introdução}

O nabo forrageiro (Raphanus sativus L. var. oleiferus Metzg.), pertencente à família Crusciferae, é uma planta anual, alógama, herbácea, ereta, muito ramificada e que pode atingir de 100 a $180 \mathrm{~cm}$ de altura (Derpsch \& Calegari, 1992). Caracteriza-se pelo cres- cimento inicial extremamente rápido, e aos 60 dias após a emergência promove a cobertura de $70 \%$ do solo (Calegari, 1990). A espécie tem sido empregada nas regiões Sul e Centro-Oeste do Brasil e no Estado de São Paulo, como material para adubação verde de inverno e planta de cobertura, em sistemas de cultivo conservacionistas como o plantio direto e o cultivo mínimo. 
A proteção do solo com cobertura vegetal tem sido objeto de estudo de vários pesquisadores na região de clima temperado (Derpsch \& Calegari, 1992). Nesta condição, a manutenção dos resíduos vegetais na superfície do solo, em sistema de plantio direto, diminui a erosão e, conseqüentemente, reduz as perdas de solo e de nutrientes, especialmente pela dissipação da energia de impacto das gotas de chuva (Pauletti, 1999). Entretanto, na região tropical, são escassos os resultados de pesquisa sobre o tema. O clima favorece a decomposição dos restos culturais, devendo-se dar atenção à quantidade e durabilidade dos resíduos vegetais produzidos pela espécie antecessora à cultura principal (Alves et al., 1995). É necessário a utilização de coberturas vegetais com a finalidade de proteção superficial do solo, formação de palhada e reciclagem de nutrientes (Lima, 2001), com a mobilização de elementos lixiviados ou pouco solúveis presentes nas camadas mais profundas do solo (Alcântara et al., 2000).

A palha na superfície do solo constitui reserva de nutrientes, cuja disponibilização pode ser rápida e intensa (Rosolem et al., 2003), ou lenta e gradual (Pauletti, 1999), dependendo da interação entre a espécie utilizada, manejo da fitomassa (época de semeadura e de corte), umidade (regime de chuvas), aeração, temperatura, atividade macro e microbiológica do solo, composição química da palha e tempo de permanência dos resíduos sobre o solo (Oliveira et al., 1999; Alcântara et al., 2000; Oliveira et al., 2002; Primavesi et al., 2002).

$\mathrm{O}$ nabo forrageiro apresenta produtividade média de $3.000 \mathrm{~kg} \mathrm{ha}^{-1}$ de massa seca da parte aérea, e, mesmo em áreas sem adubação, esse valor pode oscilar entre 2.000 e $6.000 \mathrm{~kg} \mathrm{ha}^{-1}$ de massa seca no estádio de floração (Derpsch \& Calegari, 1992; Calegari, 1998).

Quanto aos teores de nutrientes, Calegari (1990) encontrou 29,6, 1,9,39,0,21,5 e 9,5 $\mathrm{g} \mathrm{kg}^{-1}$, respectivamente, de N, P, K, Ca e Mg na massa seca da parte aérea do nabo (cv. Siletina), no florescimento (60 dias após a emergência). Ao comparar esses dados com os de diferentes espécies de inverno na região Sudoeste do Paraná, o autor verificou que o nabo destacava-se como cultura recicladora, apresentando teores elevados de $\mathrm{P}, \mathrm{K}, \mathrm{Ca} \mathrm{e}$ Mg. Por sua vez, Calegari (1998) encontrou concentrações de 26,8, 1,7, 28,0, 15,4 e 7,6 g kg-1 de N, P, K, Ca e $\mathrm{Mg}$, respectivamente, na massa seca de nabo forrageiro.

O tempo de permanência e a decomposição e liberação de nutrientes da palhada de nabo forrageiro em sistema de plantio direto com rotações e sucessões de culturas persistem como fatores pouco estudados.
O objetivo deste trabalho foi avaliar a decomposição e a liberação de macronutrientes dos resíduos de nabo forrageiro.

\section{Material e Métodos}

O experimento foi realizado no campo, em 1998, no Município de Marechal Cândido Rondon, na região Oeste do Estado do Paraná, com latitude de $24^{\circ} 31^{\prime}$ S, longitude de $54^{\circ} 31^{\prime} \mathrm{W}$ e altitude de $420 \mathrm{~m}$. O clima da região é do tipo Cfa (Köppen), ou seja, subtropical úmido mesotérmico, com verões quentes e geadas pouco freqüentes, sem estação seca definida, com tendência de concentração das chuvas nos meses de verão. Durante o período experimental, foram registradas as temperaturas máxima e mínima diárias e a precipitação pluvial diária (Figura 1).

O solo da área experimental foi classificado como Latossolo Vermelho eutroférrico nitossólico (Embrapa, 1999), muito argiloso, cujos resultados das análises granulométricas e química da camada de $0-20 \mathrm{~cm}$ de profundidade, foram: 108,2 $\mathrm{g} \mathrm{kg}^{-1}$ de areia; $180,6 \mathrm{~g} \mathrm{~kg}^{-1}$ de silte; 711,2 $\mathrm{g} \mathrm{kg}^{-1}$ de argila; $\mathrm{pH}\left(\mathrm{CaCl}_{2}\right), 4,9$; matéria orgânica (MO), $29 \mathrm{~g} \mathrm{dm}^{-3}$; $\mathrm{P}$ (Mehlich 1), $23 \mathrm{mg} \mathrm{dm}^{-3} ; \mathrm{H}+\mathrm{Al}, 58 \mathrm{mmol}_{\mathrm{c}} \mathrm{dm}^{-3} ; \mathrm{K}, \mathrm{Ca}$ e $\mathrm{Mg}$ trocáveis, $6,4,55$ e $20 \mathrm{mmol}_{\mathrm{c}} \mathrm{dm}^{-3}$, respectivamente; soma de bases $(\mathrm{SB})=81 \mathrm{mmol}_{\mathrm{c}} \mathrm{dm}^{-3}$; capacidade de troca catiônica (CTC), $139 \mathrm{mmol}_{\mathrm{c}} \mathrm{dm}^{-3}$; e saturação por bases $(\mathrm{V}), 58 \%$.

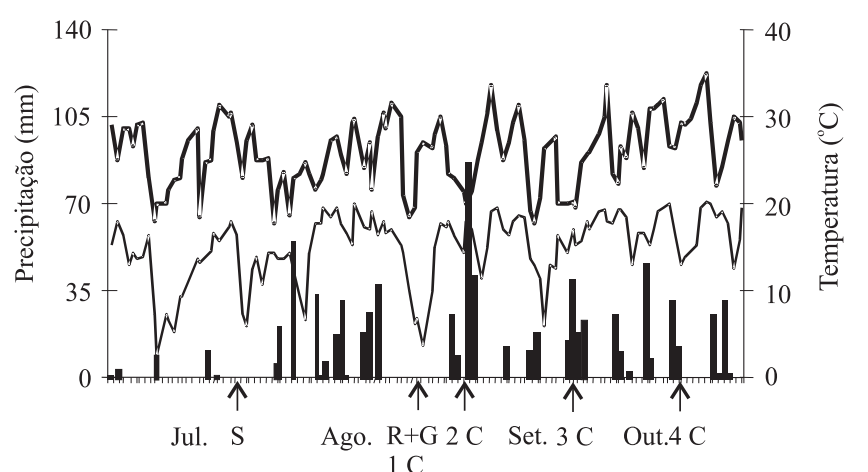

Figura 1. Temperaturas máximas $(\rightarrow$ e mínimas $(\rightarrow$, e precipitação pluvial (I) durante a condução do experimento. A semeadura ( $S$ ) foi realizada em 25/7/1998; o uso do rolofaca mais glyphosate e a primeira coleta $(\mathrm{R}+\mathrm{G}$ e $1 \mathrm{C})$ foram realizados em 28/8/1998; a segunda (2C), terceira (3C) e a quarta coleta (4C) foram realizadas, respectivamente, em 9/9, 1/10 e 19/10/1998. 
O delineamento experimental adotado foi o de blocos casualisados, com quatro repetições. Os tratamentos compreenderam quatro épocas de coleta da fitomassa da parte aérea de nabo forrageiro após o manejo $(0,13$, 35 e 53 dias). As parcelas mediam $6 \mathrm{~m}$ de largura e $10 \mathrm{~m}$ de comprimento, totalizando $60 \mathrm{~m}^{2}$.

A semeadura do nabo, cv. Siletina, foi realizada no dia 25/7/1998, em cultivo mínimo sobre palhada de feijão, numa área mantida em plantio direto durante quatro anos. Foram semeadas a lanço $20 \mathrm{~kg} \mathrm{ha}^{-1}$ de sementes que, posteriormente, foram incorporadas a $3 \mathrm{~cm}$ de profundidade com uma gradagem leve, utilizando-se discos recortados. A emergência ocorreu cinco dias após a semeadura. Adubações de semeadura e de cobertura não foram necessárias, assim como os tratos culturais, e controle de pragas e doenças.

Trinta dias após a emergência (28/8/98), no estádio de pré-florescimento, o nabo forrageiro foi manejado com rolo-faca, seguido da aplicação de $4 \mathrm{~L} \mathrm{ha}^{-1}$ (1.920 $\mathrm{g} \mathrm{ha}^{-1}$ de i.a.) de herbicida comercial à base de glyphosate. Após uma semana (5/9/1998), realizou-se a semeadura do milho sobre a palhada do nabo.

A primeira coleta do material vegetal presente na superfície do solo foi realizada no dia do manejo do nabo forrageiro (DAM); a segunda coleta, em 9/9/1998 (13 DAM); a terceira, em 1/10/1998 (35 DAM); e a quarta, em 19/10/1998 (53 DAM).

$\mathrm{Na}$ repetição de cada uma das épocas de coleta (amostras compostas), foram amostrados os resíduos contidos em três quadros de madeira, com $1 \mathrm{~m}^{2}$ de área interna (amostras simples). A coleta foi feita manualmente, com auxílio de canivete, retirando-se toda palhada superficial contida na área interna do quadro. A amostragem foi realizada diagonalmente, dentro das unidades experimentais, excluindo-se $1 \mathrm{~m}$ de cada extremidade como bordadura.

No campo, os resíduos vegetais sofreram uma prélimpeza, por meio de peneiras, para redução da quantidade de solo aderido. Os materiais vegetais foram lavados, mediante agitação por alguns segundos em água desionizada, em três porções sucessivas, sendo a seguir colocados sobre papel absorvente (Malavolta et al., 1997). A lavagem sem a utilização de detergente diminuiu o número de agitações e o tempo de exposição com a água, minimizando possíveis perdas de $\mathrm{K}$. As amostras foram acondicionadas em sacos de papel e secadas em estufa com circulação forçada de ar a $60^{\circ} \mathrm{C}$, até atingirem massa constante. A seguir, os materiais foram moídos em moinho tipo Wiley e submetidos à análise química, para determinação dos teores de macronutrientes, conforme Malavolta et al. (1997).

A quantidade de macronutrientes acumulada na palhada foi determinada pelo produto da quantidade de massa seca e os teores de nutrientes do resíduo vegetal. De posse desses valores, calculou-se a liberação de nutrientes para o solo e as porcentagens de liberação dos macronutrientes do resíduo.

Os dados obtidos foram submetidos à análises de variância e de regressão polinomial. Aplicando-se a derivada primeira às equações ajustadas aos dados de liberação acumulada de macronutrientes, calcularam-se as taxas diárias de liberação dos nutrientes após o manejo da fitomassa (Rosolem et al., 2003).

\section{Resultados e Discussão}

A semeadura do nabo forrageiro foi realizada no período de inverno (julho) (Figura 1). Nesta época há encurtamento no ciclo vegetativo e diminuição da produtividade biológica dessa espécie (Derpsch \& Calegari, 1992; Calegari, 1998). Neste trabalho, o manejo da fitomassa foi realizado 30 dias após a emergência das plantas (Figura 1). Durante o período de cultivo, houve precipitação pluvial de $251,4 \mathrm{~mm}$, obtendo-se $2.938 \mathrm{~kg} \mathrm{ha}^{-1}$ de massa seca da parte aérea. Esse resultado corrobora os de Derpsch \& Calegari (1992) e Calegari (1998), que constataram $3.000 \mathrm{~kg} \mathrm{ha}^{-1}$ de massa seca da parte aérea, quando o nabo recebeu chuvas apenas nos primeiros 30 dias após a emergência.

A decomposição dos resíduos do nabo forrageiro revelou que, aos 53 DAM, restaram somente $27,5 \%$ da quantidade inicial de fitomassa, sendo os valores ajustados à função linear (Figura 2). A palhada de nabo apre-

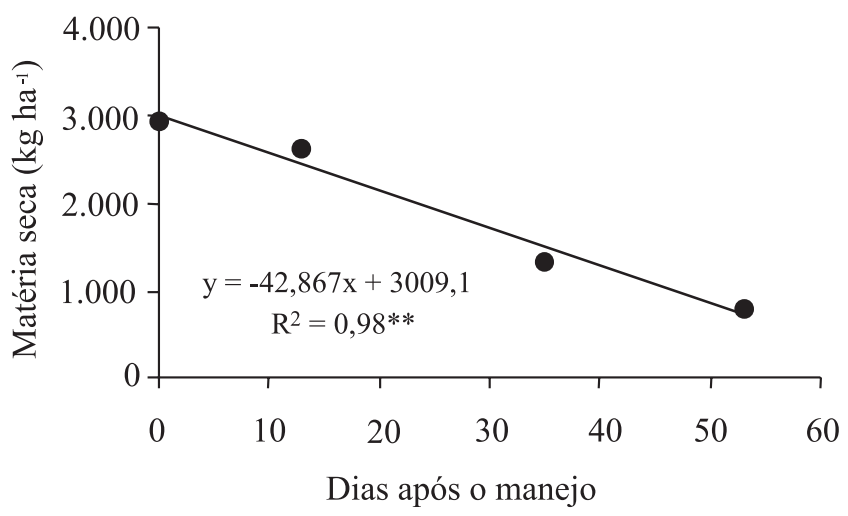

Figura 2. Quantidade de palhada de nabo forrageiro sobre o solo em função do tempo após o manejo da fitomassa. **Significativo a $1 \%$ de probabilidade pelo teste $\mathrm{F}$. 
senta baixa persistência em relação às gramíneas. A velocidade de degradação está diretamente relacionada às condições de umidade e de temperatura que atuam sobre a atividade dos organismos decompositores, ou seja, quanto maiores a temperatura e a umidade, maior a fração da fitomassa degradada (Khatounian, 1999). Além disso, outros fatores como o estádio de desenvolvimento da espécie em que foi realizado o manejo e a composição química do material vegetal cultivado justificam a velocidade de decomposição constatada.

$\mathrm{Na}$ avaliação realizada imediatamente após o manejo do nabo, verificou-se que somente o teor de $\mathrm{K}$ no tecido vegetal $\left(29,2 \mathrm{~g} \mathrm{~kg}^{-1}\right)$ era semelhante aos valores de Calegari $(1990,1998)$, que trabalhou com a mesma cultivar de nabo forrageiro utilizada no presente trabalho,
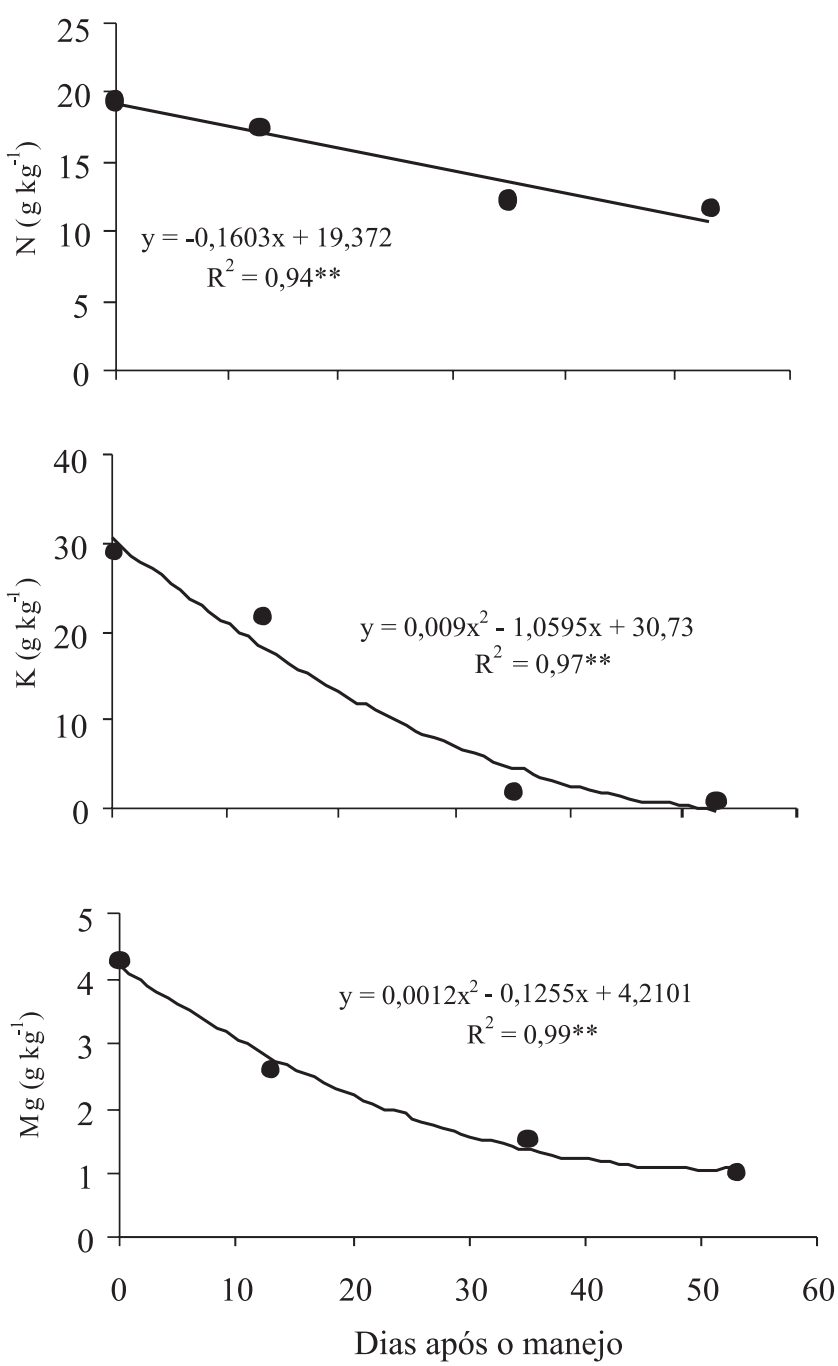

porém em semeaduras realizadas de março a maio (Figura 3). Com exceção dos teores de $\mathrm{P}\left(5,2 \mathrm{~g} \mathrm{~kg}^{-1}\right)$, os de $\mathrm{N}\left(19,6 \mathrm{~g} \mathrm{~kg}^{-1}\right), \mathrm{Ca}\left(12,6 \mathrm{~g} \mathrm{~kg}^{-1}\right)$ e $\mathrm{Mg}\left(4,2 \mathrm{~g} \mathrm{~kg}^{-1}\right)$ na planta foram menores que os observados por esses autores. A extração diferenciada de nutrientes, provavelmente, está associada às variações na fertilidade do solo entre experimentos (Primavesi et al., 2002). Em relação ao S, não foi encontrado nenhum trabalho que apresentasse teores desse elemento em nabo forrageiro, para servir de comparação aos resultados obtidos.

Na observação da degradação da massa seca sobre o solo (Figura 2), verificou-se que houve redução gradual nos teores de macronutrientes da palhada remanescente (Figura 3). Apenas os dados de $\mathrm{N}$ foram ajus-
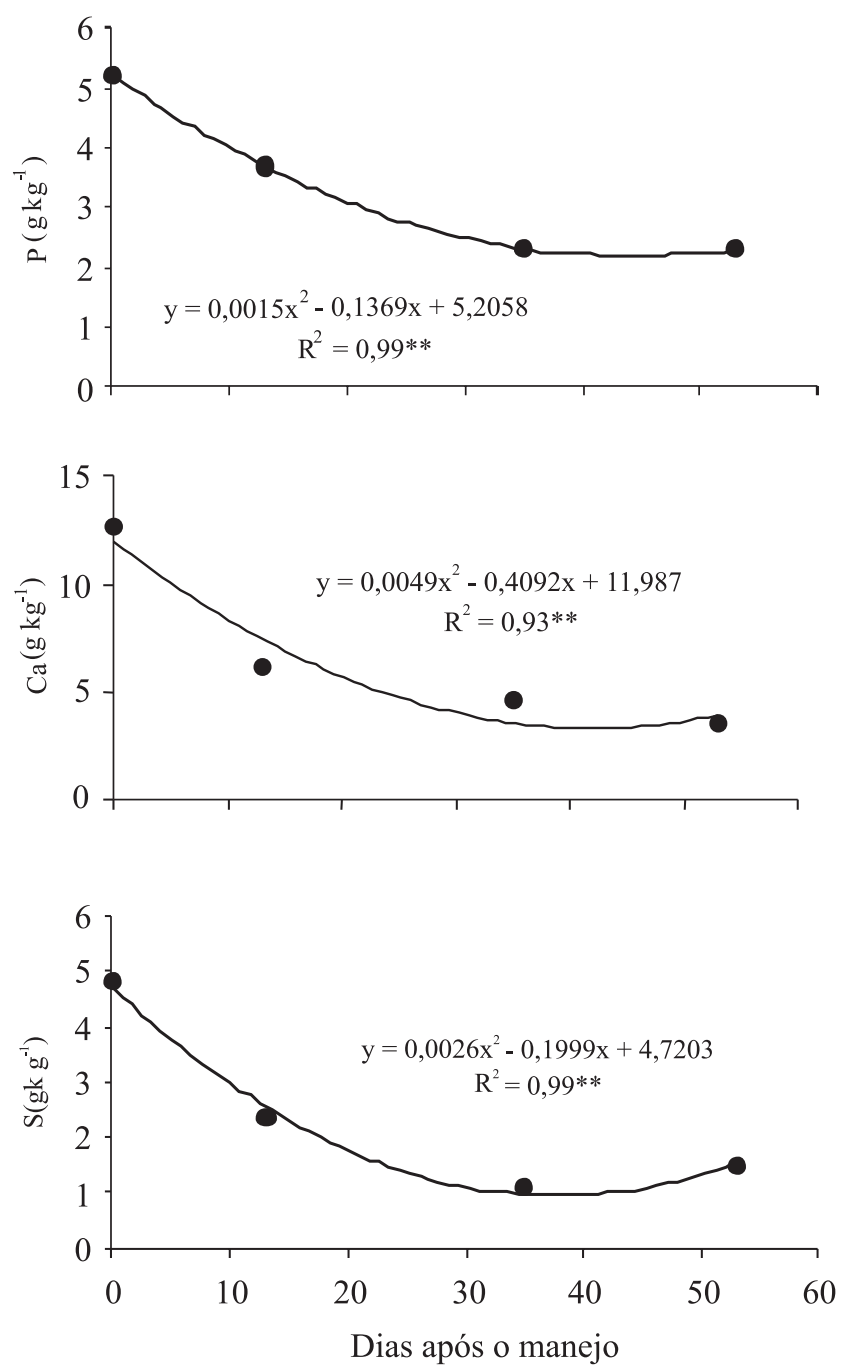

Figura 3. Teores de macronutrientes na palhada de nabo forrageiro em função do tempo após o manejo da fitomassa. **Significativo a $1 \%$ de probabilidade pelo teste $\mathrm{F}$. 
tados à função linear; quanto aos demais nutrientes, os teores foram ajustados a equações quadráticas, com tendência de estabilização a partir dos 35 DAM (Figura 3). Apenas o K, na última avaliação, apresentou teor próximo a zero. Esse nutriente não é metabolizado na planta e forma ligações com complexos orgânicos de fácil reversibilidade (Rosolem et al., 2003). Assim, à medida que a parte aérea das plantas de nabo inicia o processo de secagem e se degrada, a concentração desse nutriente no tecido diminui, pois é facilmente lavado da palhada seca pela água das chuvas (Khatounian, 1999).

Ao comparar os teores iniciais dos demais nutrientes $(\mathrm{N}, \mathrm{P}, \mathrm{Ca}, \mathrm{Mg}$ e $\mathrm{S}$ ) com os valores atingidos na última avaliação (53 DAM), verificaram-se reduções de 40,3\%, $55,8 \%, 71,4 \%, 76,8 \%$ e $79,2 \%$, respectivamente. A elevada liberação do $\mathrm{Ca}$ e do $\mathrm{Mg}$ é decorrente da participação desses elementos em compostos iônicos e moléculas solúveis (Oliveira et al., 1999).

Todas as curvas de liberação acumulada dos nutrientes foram ajustadas a equações quadráticas, cujos pontos de máxima liberação acumulada foram atingidos aos 82, 51, 49, 44, 49 e 45 DAM, para N, P, K, Ca, Mg e S, respectivamente (Figura 4).

No período de 53 DAM, em que foi avaliada a degradação do resíduo vegetal, apenas com o $\mathrm{N}$ não houve tempo suficiente para que o mesmo atingisse seu ponto
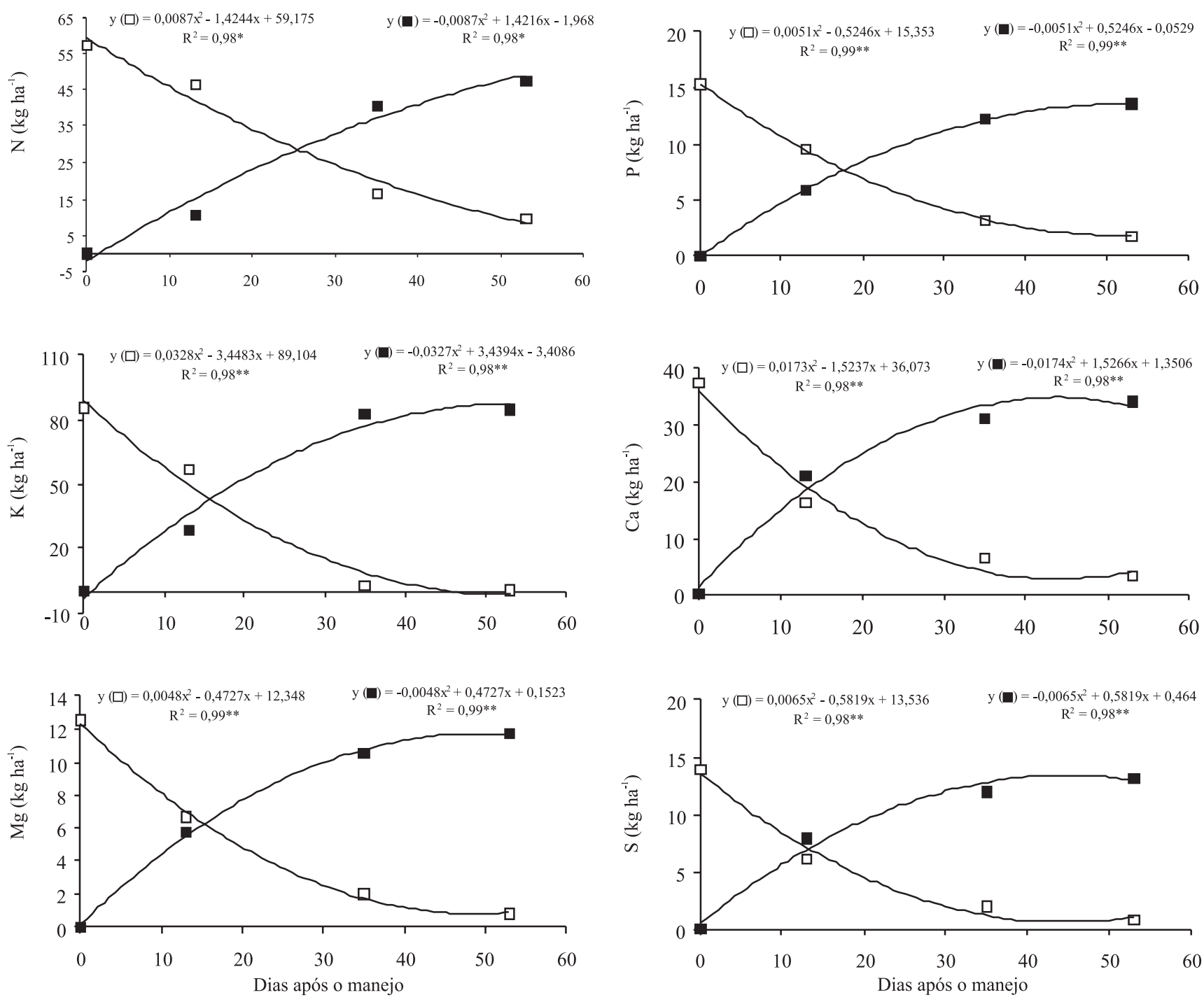

Figura 4. Quantidade de macronutrientes acumulada na palhada de nabo forrageiro ( $\square$ ) e liberação acumulada ( $\square$ ) em função do tempo após o manejo da fitomassa. * e**Significativo a $5 \%$ e a $1 \%$ de probabilidade, respectivamente, pelo teste $\mathrm{F}$. 
de máxima liberação acumulada. Isso ocorreu provavelmente por ser esse nutriente absorvido em maior quantidade, o que proporciona seu maior acúmulo na fitomassa. Assim, a quantidade a ser liberada é maior que a dos demais nutrientes, levando mais tempo para que a quantidade acumulada seja igual à liberada. Esse fato passa a ser pouco relevante quando se verifica que, já aos $35 \mathrm{DAM}$, mais de $40 \mathrm{~kg} \mathrm{ha}^{-1}$ de $\mathrm{N}$ foram liberados da palhada, representado aproximadamente $65 \%$ do total (Figura 5). Esse resultado, em termos de quantidade, corrobora os dados de Ceretta et al. (2002), quanto ao cultivo de nabo forrageiro, em que a quantidade de $\mathrm{N}$ liberado do resíduo atingiu mais de $36 \mathrm{~kg} \mathrm{ha}^{-1}, 30$ dias após a dessecação. Ficou evidente que uma vez fixado em compostos orgânicos, o $\mathrm{N}$ fica à disposição da
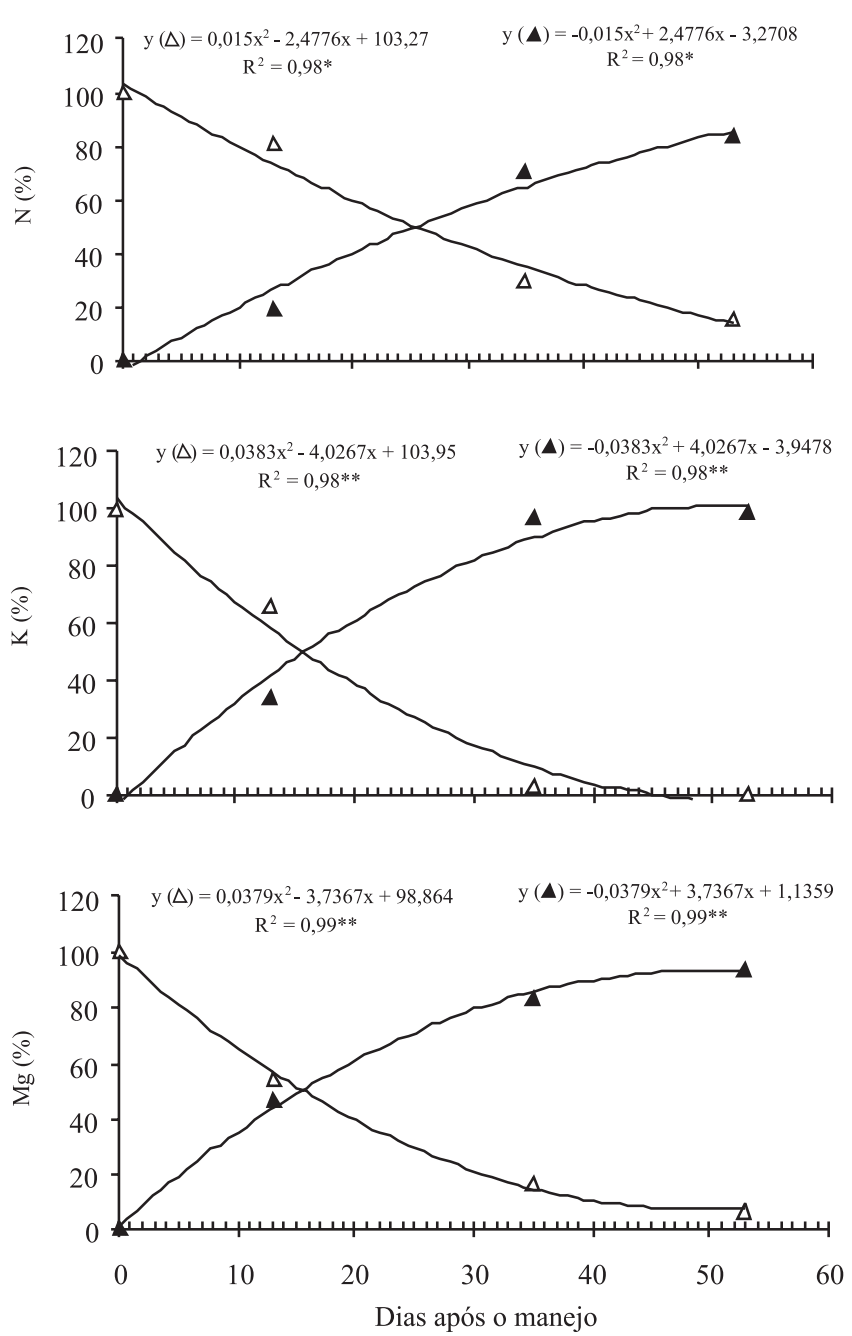

ciclagem no complexo planta-palha-solo, formado pelos agroecossistemas. $\mathrm{O}$ ponto de intersessão em que a porcentagem dos macronutrientes acumuladas no resíduo foi igual à porcentagem dos macronutrientes liberados para o solo, ocorreu aos 26 e 18 DAM em relação ao $\mathrm{N}$ e ao $\mathrm{P}$, respectivamente, $16 \mathrm{DAM}$ em relação ao $\mathrm{K}$ e $\mathrm{Mg}$ e 14 DAM quanto ao Ca e S (Figura 5). Apenas quanto ao $\mathrm{N}$, a equivalência entre essas duas variáveis ocorreu em período superior a 20 dias do manejo da cobertura de solo. Resultado semelhante foi constatado por Ceretta et al. (2002), sendo que 30 dias após dessecação do nabo, a quantidade de $\mathrm{N}$ liberada do resíduo correspondeu a 50\% do total acumulado.

A maior velocidade de liberação de todos os elementos ocorreu entre 10 e 20 DAM da fitomassa, indicando rápida liberação inicial dos macronutrientes (Figura 6).
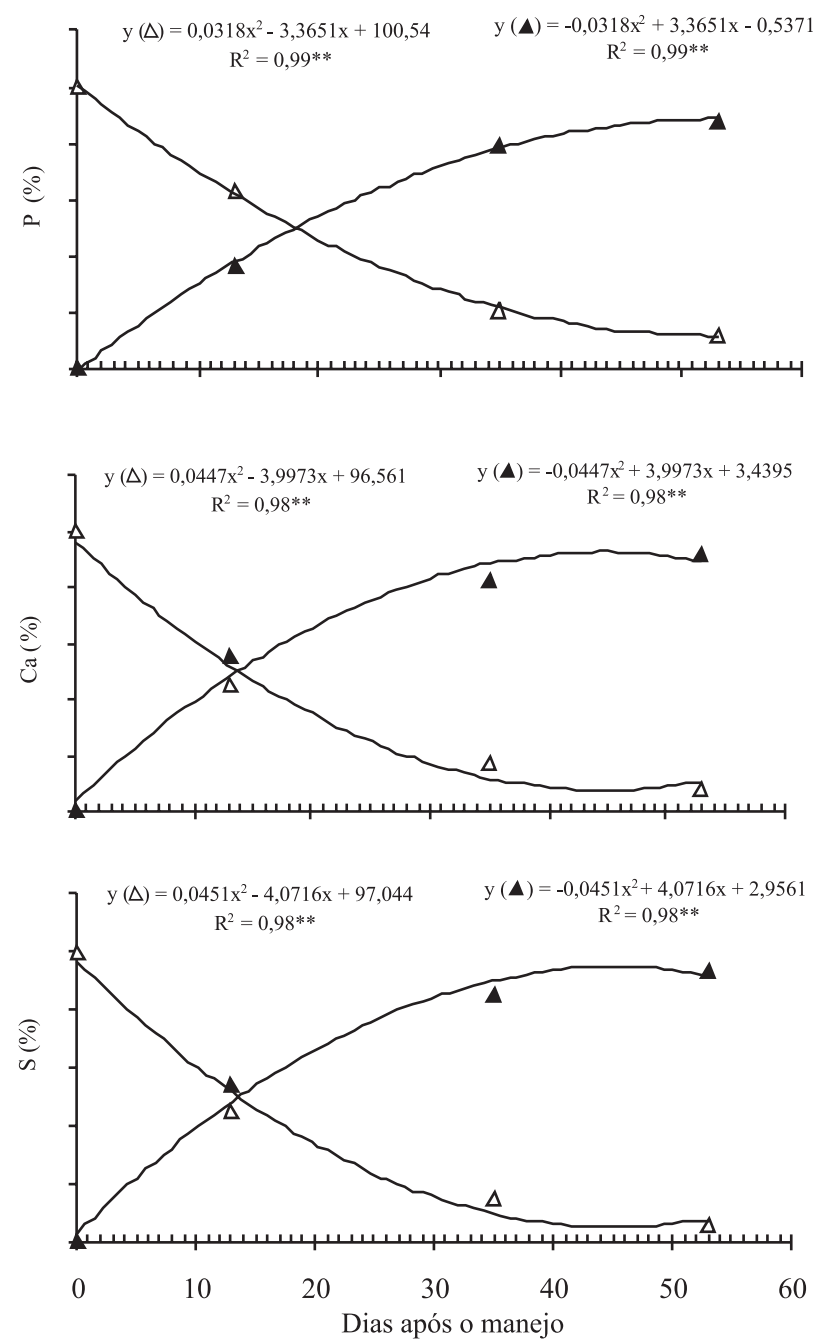

Figura 5. Porcentagem do total de macronutriente acumulado na palhada de nabo forrageiro $(\triangle)$ e porcentagem de liberação acumulada $(\boldsymbol{\Delta})$ em função do tempo após o manejo da fitomassa. * e **Significativo a $5 \%$ e a $1 \%$ de probabilidade, respectivamente, pelo teste $\mathrm{F}$. 

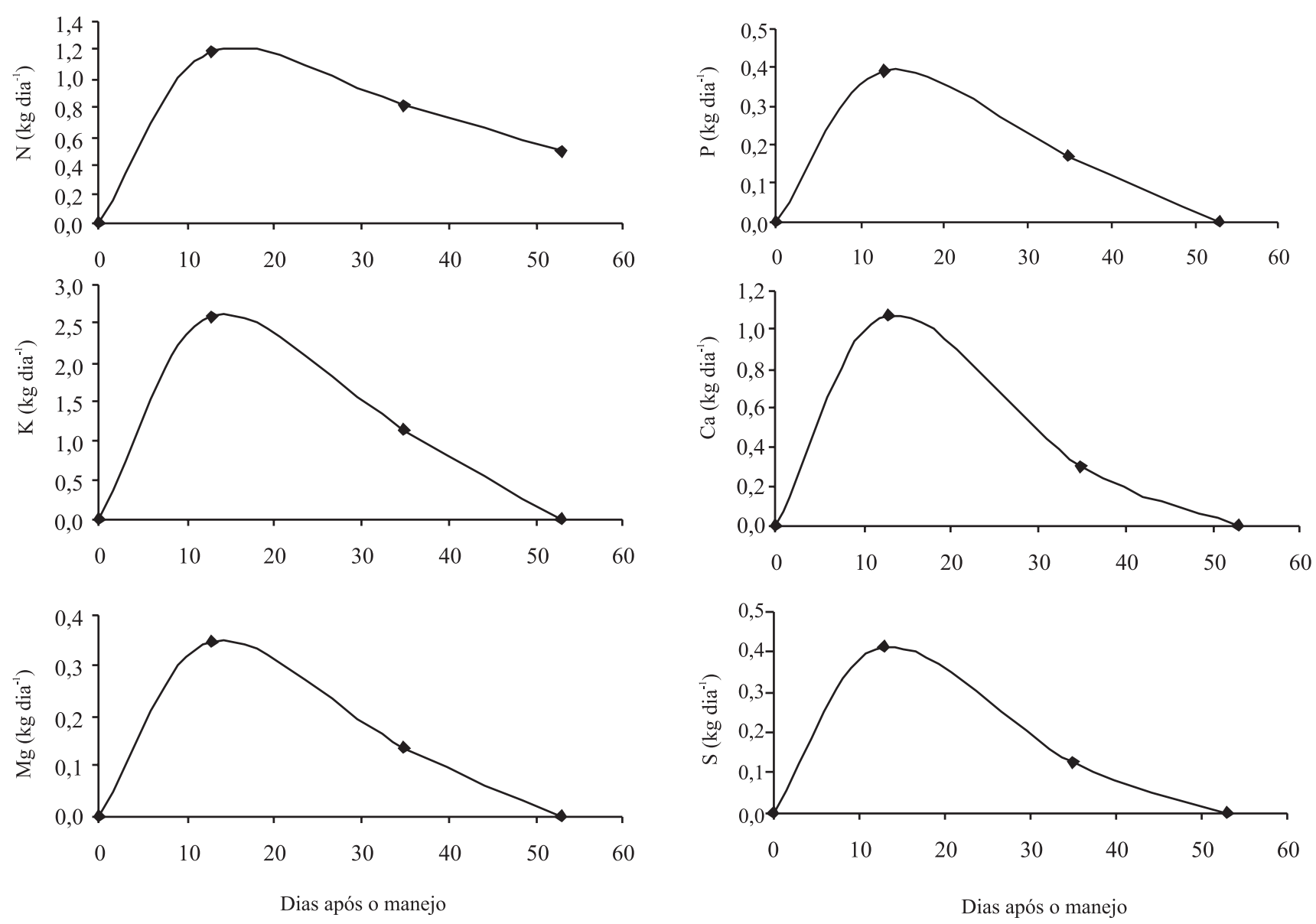

Figura 6. Taxa diária de liberação dos macronutrientes da palhada de nabo forrageiro em função do tempo após o manejo da fitomassa.

De modo geral, houve aumento da velocidade de liberação dos macronutrientes até, aproximadamente, 10 DAM, com redução continua, a partir de 15 DAM, e posterior tendência à estabilização em valores próximo a zero.

Com a elevada decomposição e liberação de nutrientes do nabo forrageiro no período inicial é possível inferir que, para maximizar o aproveitamento desses elementos, a implantação da cultura subseqüente deve ser realizada com maior antecedência possível após o manejo da planta de cobertura. Essa mesma sugestão foi feita por Ceretta et al. (2002). Quanto ao K, o nabo forrageiro disponibilizou, de imediato (13 DAM), quantidade superior a $25 \mathrm{~kg} \mathrm{ha}^{-1}$, o que corresponde a mais de $30 \mathrm{~kg} \mathrm{ha}^{-1}$ de $\mathrm{K}_{2} \mathrm{O}$, num período em que a demanda da cultura subseqüente não é alta, podendo, portanto, ser suficiente para sua demanda inicial. Observação semelhante foi feita por Rosolem et al. (2003). Nesse mesmo período, $5,8 \mathrm{~kg} \mathrm{ha}^{-1} \mathrm{de} \mathrm{P}$ foi liberado dos tecidos orgânicos, que podem ficar disponíveis tanto para absorção quanto para imobilização em compostos minerais de difícil solubilidade (Khatounian, 1999).

\section{Conclusões}

1. O nabo forrageiro produz, até o estádio de préflorescimento, elevada quantidade de parte aérea em cultivo de inverno, acumulando 57,2, 15,3, 85,7, 37,4, 12,5 e 14,0 $\mathrm{kg} \mathrm{ha}^{-1}$, respectivamente, de N, P, K, Ca, Mg e S.

2. O manejo do nabo forrageiro no estádio de préflorescimento apresenta rápida degradação da palhada, liberando quantidades substanciais de macronutirentes.

3. O K e N são os nutrientes disponibilizados em maior quantidade e velocidade para a cultura subseqüente.

4. A maior velocidade de liberação de macronutrientes pelo nabo forrageiro ocorre entre 10 e 20 dias após o manejo da fitomassa. 


\section{Referências}

ALCÂNTARA, F.A.; FURTINI NETO, A.E.; DE PAULA, M.B.; MESQUITA, H.A.; MUNIZ, J.A. Adubação verde na recuperação da fertilidade de um Latossolo Vermelho-Escuro degradado. Pesquisa Agropecuária Brasileira, v.35, p.277-288, 2000.

ALVES, A.G.C.; COGO, N.P.; LEVIEN, R. Relações da erosão do solo com a persistência da cobertura vegetal morta. Revista Brasileira de Ciência do Solo, v.19, p127-132, 1995.

CALEGARI, A. Espécies para cobertura de solo. In: DAROLT, M.R. (Coord.). Plantio direto: pequena propriedade sustentável. Londrina: Iapar, 1998. p.65-94. (Circular, 101).

CALEGARI, A. Plantas para adubação verde de inverno no sudoeste do Paraná. Londrina: Iapar, 1990. 37p. (Boletim Técnico, 35).

CERETTA, C.A.; BASSO, C.J.; HERBES, M.G.; POLETTO, N.; SILVEIRA, M.J. Produção e decomposição de fitomassa de plantas invernais de cobertura de solo e milho, sob diferentes manejos da adubação nitrogenada. Ciência Rural, v.32, p.49-54, 2002.

DERPSCH, R.; CALEGARI, A. Plantas para adubação verde de inverno. Londrina: Iapar, 1992. 80p. (Circular, 73).

EMBRAPA. Centro Nacional de Pesquisa de Solos. Sistema brasileiro de classificação de solo. Rio de Janeiro: Embrapa, 1999. 412p.

KHATOUNIAN, C.A. O manejo da fertilidade em sistemas de produção. In: CASTRO FILHO, C.; MUZILLI, O. (Coord.). Uso e manejo dos solos de baixa aptidão agrícola. Londrina: Iapar, 1999. p.179-221. (Circular, 108).
LIMA, E. do V. Alterações dos atributos químicos do solo e resposta da soja à cobertura vegetal $\mathrm{e}$ à calagem superficial na implantação do sistema de semeadura direta. 2001. 125p. Dissertação (Mestrado) - Universidade Estadual Paulista, Botucatu.

MALAVOLTA, E.; VITTI, G.C.; OLIVEIRA, S.A. Avaliação do estado nutricional de plantas: princípios e aplicações. Piracicaba: Potafos, 1997. 308p.

OLIVEIRA, M.W.; TRIVELIN, P.C.O.; PENATTI, C.P.; PICCOLO, M.C. Decomposição de nutrientes da palhada de cana-de-açúcar em campo. Pesquisa Agropecuária Brasileira, v.34, p.2359-2362, 1999.

OLIVEIRA, T.K.; CARVALHO, G.J.; MORAES, R.N.S. Plantas de cobertura e seus efeitos sobre o feijoeiro em plantio direto. Pesquisa Agropecuária Brasileira, v.37, p.1079-1087, 2002.

PAULETTI, V. A importância da palhada e da atividade biológica na fertilidade do solo. In: CURSO SOBRE ASPECTOS BÁSICOS DE FERTILIDADE E MICROBIOLOGIA DO SOLO EM PLANTIO DIRETO, 3., 1999, Cruz Alta. Palestras. Passo Fundo: Aldeia Norte, 1999. p.56-66.

PRIMAVESI, O.; PRIMAVESI, A.C.; ARMELIN, M.J.A. Qualidade mineral e degradabilidade potencial de adubos verdes conduzidos sobre Latossolos, na região tropical de São Carlos, SP, Brasil. Revista de Agricultura, v.77, p.89-102, 2002.

ROSOLEM, C.A.; CALONEGO, J.C.; FOLONI, J.S.S. Lixiviação de potássio da palhada de espécies de cobertura de solo de acordo com a quantidade de chuva aplicada. Revista Brasileira de Ciência do Solo, v.27, p.355-362, 2003.

Recebido em 21 de julho de 2003 e aprovado em 16 de dezembro de 2004 